\title{
A first application of a marine inductive source EM configuration with remote electric dipole receivers: Palinuro Seamount, Tyrrhenian Sea
}

Roxana Safipour ${ }^{1}$, Sebastian Hölz ${ }^{2}$, Marion Jegen ${ }^{2}$, Andrei Swidinsky ${ }^{1}$

1. Colorado School of Mines

Department of Geophysics

1500 Illinois St., Golden, CO, 80401, USA.

E-mail: rsafipou@mines.edu

2. GEOMAR, Helmholtz Centre for Ocean Research

Geodynamics Department

Wischhofstr. 1-3, 24148 Kiel, Germany 


\section{Abstract}

We study a new marine electromagnetic configuration which consists of a ship-towed inductive source transmitter and a series of remote electric dipole receivers placed on the seafloor. The approach was tested at the Palinuro Seamount in the southern Tyrrhenian Sea, at a site where massive sulfide mineralization has been previously identified by shallow drilling. A 3D model of the Palinuro study area was created using bathymetry data, and forward modeling of the electric field diffusion was carried out using a finite volume method. These numerical results suggest that the remote receivers can theoretically detect a block of shallowly-buried conductive material at up to $\sim 100 \mathrm{~m}$ away when the transmitter is located directly above the target. We also compared the sensitivity of the method using either a horizontal loop transmitter or a vertical loop transmitter and found that when either transmitter is located directly above the mineralized zone, the vertical loop transmitter has sensitivity to the target at a farther distance than the horizontal loop transmitter in the broadside direction by a few 10s of meters. Furthermore, the vertical loop transmitter is more effective at distinguishing the seafloor conductivity structure when the vertical separation between transmitter and receiver is large due to the bathymetry. As a horizontal transmitter is logistically easier to deploy, we conducted a first test of the method with a horizontal transmitter. Apparent conductivities are calculated from the electric field transients recorded at the remote receivers. The analysis indicates higher apparent seafloor conductivities when the transmitter is located near the mineralized zone. Forward modeling suggests that the best match to the apparent conductivity data is obtained when the mineralized zone is extended southward by $40 \mathrm{~m}$ beyond the zone of previous drilling. Our results demonstrate that the method adds value to the exploration and characterization of seafloor massive sulfide deposits. 
Keywords: 3D, Marine, Electromagnetics 


\section{Introduction}

Seafloor massive sulfide (SMS) deposits are a potential source of base and precious metal resources, and lately interest in exploring for and economically exploiting these deposits has been increasing (Kowalczyk, 2008). Transient electromagnetic (TEM) and controlled-source electromagnetic (CSEM) surveys have both played a role in the exploration and investigation of these marine mineral resources. Marine TEM methods typically employ an inductive source loop transmitter and coincident or in-loop receiver that is either mounted on an ROV or towed behind a ship. Marine TEM systems have been applied to detecting and characterizing SMS deposits (Kowalczyk, 2008; Hölz et al., 2015a; Nakayama and Saito, 2016; Asakawa et al., 2016). Marine CSEM systems typically employ a ship-towed electric dipole transmitter and electric dipole receivers placed on the seafloor. Marine CSEM methods have been successfully applied in detecting and characterizing SMS deposits and other small targets (Wolfgram et al., 1986; Cairns et al., 1996), oil and gas reserves (see Constable 2010 for a review), and gas hydrates (Yuan and Edwards, 2000; Weitemeyer et al., 2006a; Schwalenberg et al., 2010a,b; Hölz et al., 2015b; Swidinsky et al., 2015; Constable et al., 2016).

We describe a new marine EM configuration which combines the advantages of TEM and CSEM systems. TEM systems with the receiver either coincident or concentric to the transmitter are primarily sensitive to the seafloor conductivity structure directly below or close to the system, which is a useful property when attempting to pinpoint the location of a small target. Conversely, a CSEM system with an array of remote dipole receivers covering the area of interest has a broader sensitivity to the structure of the seafloor throughout the survey area. It should also be noted that CSEM systems use galvanic (electric dipole) sources as opposed to inductive (magnetic dipole) sources, and based on the different underlying physics, have different sensitivity to subsurface structure. Our configuration, referred to as "Coil2Dipole", consists of a transmitter and coincident receiver loop towed behind a ship and an array of dipole receivers placed on the seafloor (Figure 
1) (Safipour et al., 2017b). The data recorded by the towed receiver loop provide narrowly-sensitive data along the towing path, while the remote receivers provide data which are broadly sensitive to the conductivity structure of the whole survey area. In addition, the remote receivers are sensitive to greater depths within the seafloor than the towed loop receiver, because of the effect of offset between transmitter and receiver. Thus the configuration has the capability to both pinpoint the location of small targets and detect additional targets which are not close enough to the towing path or too deep to be detected by a standard TEM system. Potential targets identified in the data from the remote receivers could then be investigated in detail by towing the system directly over them in a follow-up survey.

Previously, a marine system which combines a self-contained towed system with remote receivers has been tested in gas hydrate exploration; Constable et al. (2016) developed and tested a CSEM system consisting of a galvanic electric dipole transmitter and an array of self-contained 3-component dipole receivers towed behind a ship with additional stationary dipole receivers placed on the seafloor. A CSEM system with a towed dipole transmitter and remote dipole receivers, but without towed receivers, was also tested for gas hydrate detection in the shallow seafloor by Weitemeyer et al. (2006a,b). A TEM system consisting of a loop transmitter and remote electric dipole receivers has been tested in land-based applications (Macnae and Irvine, 1988; Macnae et al., 1989). However, to our knowledge, a system consisting of an inductive source transmitter and remote dipole receivers has not been tested in a marine setting prior to this study.

In a previous paper, we studied the theoretical capabilities of the Coil2Dipole configuration and briefly examined the remote receiver data from our first test of the configuration using a 1D forward modeling approach (Safipour et al., 2017b). However, a more thorough interpretation of the data requires a 3D approach, as the bathymetry of the study area and the 3D nature of the SMS target are not considered in a 1D model. In this study we examine the theoretical capabilities of the Coil2Dipole configuration using 3D 
forward modeling. We compare the capabilities of the configuration using either a horizontal or vertical loop transmitter, and we examine the effect of the transmitter position relative to the edge of a buried conductive target body. Finally, we use an apparent conductivity method to interpret the data recorded by the remote receivers during the first test of the configuration.

While this study focuses exclusively on inductive source (magnetic dipole) transmitters, we note that the use of a galvanic source (electric dipole) transmitter, rather than a loop, may be advantageous when sensitivity to a greater depth of investigation within the seafloor is required. While the depth sensitivity of a loop transmitter can be improved by increasing the radius of the loop, a very large loop may be logistically difficult to deploy from a ship. Increasing the transmitter moment by increasing the number of turns of wire in the coil has the disadvantage that the ramp time at current shut-off increases, and a large number of turns in the coil is thus ineffective in time-domain EM systems. Conversely, a large electric dipole transmitter may be easier to deploy from a ship. The use of galvanic source transmitters and their comparison with loop sources is beyond the scope of our study, but it presents an interesting topic for future work.

\section{A First Test of the Coil2Dipole Configuration}

The transmitter of the Coil2Dipole configuration is a square frame $4.3 \times 4.3 \mathrm{~m}$ containing two windings of wire with a current of $38 \mathrm{~A}$ that is suspended horizontally $15 \mathrm{~m}$ below a cubical container for the system electronics (Figure 2A). The coincident-loop receiver and data logger are also affixed to the square frame. The transmitter is lowered off the back of the ship via an A-frame winch, and an on-board altimeter tracks the height of the system above the seafloor; during deployment the cable length is constantly adjusted to maintain the transmitter altitude between 5-10 m. Prior to deploying the frame, ocean-bottom receivers consisting of two perpendicular arms $10 \mathrm{~m}$ in length with $\mathrm{Ag}-\mathrm{AgCl}$ electrodes on the ends are deployed throughout the survey area (Figure 2C). The 
ocean-bottom receivers are affixed to a titanium frame with bouyant foam blocks and are kept on the seafloor by concrete slab anchors. When the survey is complete, acoustic pings are used to signal the receivers to release their anchors and float back to the surface where they can be recovered. The electric field transients recorded by the receivers are stacked to obtain a single transient decay curve for each transmission. The system electronics are described in detail by Hölz et al. (2015a).

Our first test of the Coil2Dipole configuration was carried out at the Palinuro Seamount in the Tyrrhenian Sea (Figure 3) during the research cruise POS483 (R/V Poseidon, Mar. 28 - Apr. 15, 2015). Massive sulfide samples were first discovered at Palinuro by Minniti and Bonavia (1984) and shallow drilling carried out by Petersen et al. (2014) recovered sulfides in 11 drill cores. The drill cores indicate that the massive sulfides are typically buried under several meters of mud, making Palinuro a good test site for the exploration of a shallowly buried deposit. Gravity, magnetic, sonar backscatter reflectivity, and detailed bathymetry data had previously been collected over the area of the sulfides (Caratori Tontini et al., 2014; Ligi et al., 2014). In addition, during the POS509 research cruise in February 2017, a self-potential experiment detected high natural electric field strengths over the massive sulfide mineralization (Safipour et al., 2017a), and heat flow data collected at the site indicated elevated seafloor temperatures over the known mineralization and extending $\sim 35$ m southward. Electromagnetic methods had not been tested at Palinuro prior to these cruises.

For the test at Palinuro, ocean-bottom receivers were deployed throughout the survey area; unfortunately, due to a failure of the data cards only two receivers recorded electric fields during the experiment, RX09 and RX11. The transmitter loop was lowered to a height of $5-10 \mathrm{~m}$ above the seafloor and towed past the site of the known SMS mineralization, and 84 transmissions were made along the towing path which were recorded by the two receivers (Figure 4). The separation distance between transmission sites and receivers ranged from $80 \mathrm{~m}$ to $300 \mathrm{~m}$. Transients were recorded by both RX09 and RX11 
for most of the transmissions, though at some of the largest separation distances a transient could not be clearly identified in the data. A total of 111 transients of good quality were recorded by the remote receivers (Figure 5), while 57 of the transmitter-receiver combinations had too large of an offset for a transient to be detected. The orientation of the receivers' electrode arms is arbitrary, however, since the electrode arms are perpendicular, we can calculate the magnitude of the total horizontal electric field, $E_{h}$, from the fields $E_{1}$ and $E_{2}$ recorded by the two electrode arms:

$$
E_{h}=\sqrt{E_{1}^{2}+E_{2}^{2}}
$$

In this study, we we work with the quantity described in equation (1) as the basic measurement of the Coil2Dipole configuration, and examine the data recorded by the remote receivers. An examination of the data from the coincident-loop receiver, known individually as the Marine Transient Electromagnetic (MARTEMIS) System, is covered by Hölz et al. (2015a).

\section{A 3D Forward Modeling Approach}

We gained access to a finite-volume 3D time-domain EM forward modeling code produced at the University of British Columbia (Haber, 2015). Using this code we created a 3D block model of the Palinuro survey area using the bathymetry data. We assigned the seawater a conductivity of $4.6 \mathrm{~S} / \mathrm{m}$ which is consistent with the seawater conductivity measured by CTD probe during the experiment. The seafloor conductivity was set to 1 $\mathrm{S} / \mathrm{m}$ to represent host rock saturated with seawater. To include the effect of the sulfides, we placed a block with a conductivity of $10 \mathrm{~S} / \mathrm{m}$ with dimensions $55 \mathrm{~m}$ x $35 \mathrm{~m}$ x $30 \mathrm{~m}$ thick buried at $5 \mathrm{~m}$ below the seafloor surface at the site of the previously drilled massive sulfide mineralization, indicated by the green square in Figure 4. The lateral dimensions of this block correspond to the extents of the area where massive sulfides were recovered 
from drill holes, however, the true lateral extents of the mineralization are unknown and could be larger, hence the purpose of the geophysical surveys in the area. The depth extent of the mineralization is also unconstrained by the drill holes. The burial depth of $5 \mathrm{~m}$ was chosen because the drill holes indicated the mineralization was buried under several meters of mud. We ran the forward model with a transmitter of $2 \mathrm{~m}$ radius and $50 \mathrm{~A}$ current located $10 \mathrm{~m}$ above the seafloor directly above the center of the buried conductive block.

The electric fields were calculated at a grid of receivers on the seafloor surface spaced $50 \mathrm{~m}$ apart. In this way we were able to model and visualize how the total horizontal electric field moves outward from the transmitter across the seafloor topography for both a horizontal transmitter (Figure 6) and a vertical transmitter with the loop axis aligned in an E-W direction (Figure 7). While the actual experiment at Palinuro was conducted with only a horizontal loop transmitter, modeling both a horizontal and vertical transmitter allows us to make some theoretical inferences about the relative sensitivity of the two systems. The pattern of electric field diffusion across the seafloor is similar for both the vertical and horizontal loop transmitters, although with a vertical transmitter the fields diffuse outward slightly faster in the direction broadside to the transmitter loop axis.

As a reference, we also modeled the horizontal electric field magnitude for a purely homogeneous seafloor. Figures 8 and $\mathbf{9}$ show the absolute difference in horizontal electric field magnitude between the homogeneous seafloor model and the model containing the 10 $\mathrm{S} / \mathrm{m}$ conductive mineralized block. To assess the detectability of the target by our instrumentation, we include a red contour line on the images that indicates a field strength of $2 \times 10^{-8} \mathrm{~V} / \mathrm{m}$, which is the approximate noise floor of our receivers. From the modeling we see that the system is sensitive to the presence of the conductive block at distances up to $\sim 100 \mathrm{~m}$ away from the target, and the vertical loop system is sensitive to a few 10s of meters farther distances than the horizontal loop system in the N-S direction. We next ran the models with the transmitter located $50 \mathrm{~m}$ to the east of the edge of the mineralized zone. The conductive block is still detectable, but now only at closer distances to the 
target ( $\sim 50 \mathrm{~m}$ away), and the sensitivity appears about the same for both the horizontal and vertical loop transmitters. Finally, we ran the models with the transmitter located 100 $\mathrm{m}$ to the east of the edge of the mineralized zone (Figures 10 and 11). For this case the conductive block is only detectable by a receiver located directly above the mineralized zone.

Safipour et al. (2017b) investigated the vertical bounds of detectability of a layered deposit using 1D analysis. With 3D modeling we can now extend this analysis to characterize lateral bounds of detectability. In particular, we examined the horizontal electric field transients for a horizontal transmitter with a $2 \mathrm{~m}$ radius and $50 \mathrm{~A}$ current at a receiver located on the seafloor directly centered over the buried conductive block. We model the conductive target block with lateral extents confined to the drilling zone (green square in Figure 4), and also with the eastern boundary of the conductive target extended by $20 \mathrm{~m}, 40 \mathrm{~m}$, and $60 \mathrm{~m}$ and with the western boundary of the target extended by $20 \mathrm{~m}$, $40 \mathrm{~m}$, and $60 \mathrm{~m}$. Figure $\mathbf{1 2 C}$ shows the transients when the transmitter is located $10 \mathrm{~m}$ above the seafloor $100 \mathrm{~m}$ to the east of the receiver. Due to the relatively flat bathymetry east of the target (Figure 12A), the transmitter has a height of $10 \mathrm{~m}$ above the height of the receiver. The system cannot distinguish between the case of the target confined to the drilling zone and the extension of the target to the west, which is not a surprising result given that the system should be mostly sensitive to the seafloor conductivity structure between the transmitter and receiver. However, the system can distinguish between the drilling zone target and the target which is extended to the east by $60 \mathrm{~m}$, as the difference in amplitude of the transient is greater than the approximate measurement error of the receivers at $2 \times 10^{-8} \mathrm{~V} / \mathrm{m}$. Figure $12 \mathrm{D}$ shows the transients when the transmitter is located $10 \mathrm{~m}$ above the seafloor $100 \mathrm{~m}$ to the west of the receiver. The bathymetry is uphill to the west of the target (Figure 12B), so the transmitter now has a height of $40 \mathrm{~m}$ above the height of the receiver, and the burial depth of the target increases to the west. In this case, the system cannot distinguish between the conductive block confined to the drilling 
zone and the conductive block that is extended to the west. The increased target burial depth and increased height of the transmitter above the receiver, both resulting from the bathymetry, are likely factors that cause the system to be less sensitive to the changes in the target boundaries when the transmitter is west of the target, as opposed to when it is east of the target.

We also examine the horizontal electric field transients for a vertical loop transmitter with its axis aligned in an E-W direction with a $2 \mathrm{~m}$ radius and $50 \mathrm{~A}$ current at a receiver located on the seafloor directly centered over the buried conductive block.

Figure 12E shows the transients for the case when the transmitter is located $10 \mathrm{~m}$ above the seafloor $100 \mathrm{~m}$ east of the receiver, and Figure $\mathbf{1 2 F}$ shows the transients for the case when the transmitter is located $10 \mathrm{~m}$ above the seafloor $100 \mathrm{~m}$ west of the receiver. Unlike with the horizontal transmitter, the system can now distinguish between the conductive target that is confined to the drilling zone and the target that is extended to the west when the transmitter is located $100 \mathrm{~m}$ west of the receiver, and the system does a better job of distinguishing the various eastward target extensions when the transmitter is located 100 $\mathrm{m}$ east of the receiver. This suggests that the vertical transmitter is less sensitive to the effects of the underlying bathymetry and increased height between the transmitter and receiver caused by moving the transmitter uphill, which may result from the larger vertical component of the electric field induced by the vertical transmitter.

We also ran all of the models for the case where the transmitter is located $10 \mathrm{~m}$ directly above the receiver, centered over the conductive target. For both the horizontal and vertical loop transmitters, the system is unable to distinguish between any of the models with the target boundaries extended to the east or west. This is an expected result, as when the transmitter is located directly above the receiver the system is primarily sensitive to the seafloor conductivity structure directly below the receiver and has limited lateral imaging ability.

\section{Apparent Conductivity Analysis}


We conduct a preliminary analysis of the data recorded by the remote receivers by calculating apparent conductivities. We use the method derived by Swidinsky et al. (2015), where for a 1D double halfspace model the apparent conductivity of the lower halfspace can be calculated from the arrival time of the peak of the $E_{h}$ transient. We are only interested in the apparent conductivity of the lower halfspace, which represents the seafloor, while the upper halfspace representing the seawater is assumed to be of relatively constant conductivity throughout the survey area. The apparent conductivity of the seafloor, $\sigma$, is calculated from the arrival time of the peak of the transient, $\tau$, and the 3D separation distance between the transmitter and receiver, $R$, as:

$$
\sigma=\frac{\tau c}{\mu R^{2}}
$$

Where $\mu$ is the permeability of free space and $c$ is a scaling constant. For any given double halfspace model, $c$ can be calculated numerically via 1D forward modeling. We use a double halfspace model with an upper halfspace conductivity of $4.6 \mathrm{~S} / \mathrm{m}$, which is consistent with the seawater conductivity measured at Palinuro, and a lower halfspace conductivity of $1 \mathrm{~S} / \mathrm{m}$, representing the seafloor. For each transmitter and receiver pair, the transient is forward modeled using the routine from Safipour et al. (2017b) and the value of $c$ needed to return the correct apparent conductivity of $1 \mathrm{~S} / \mathrm{m}$ is calculated. The peak arrival time is then picked from the real data for the same transmitter-receiver pair, and an apparent conductivity is calculated using this numerically derived value of $c$.

As the calculation of $c$ is somewhat dependent on the initial guess at seafloor conductivity used in the 1D forward model, apparent conductivities are best for making inferences about the relative conductivity of the seafloor throughout the survey area rather than identifying the true conductivity. Thus after calculating an apparent conductivity for each transmitter-receiver pair, we convert each apparent conductivity, $\sigma_{n}$, to a Z-score, $Z_{n}$, representing how many standard deviations the apparent conductivity is above or below 
the mean of the data (eg. Singer and Kouda, 2001):

$$
Z_{n}=\frac{\sigma_{n}-m}{s}
$$

Where $m$ is the mean of the apparent conductivities and $s$ is the standard deviation. The use of Z-scores allows us to identify where the apparent conductivity of the seafloor is higher or lower than average. We plot the Z-scores of apparent conductivity at the midpoint between each transmitter-receiver pair, as the apparent conductivity is most sensitive to the conductivity structure of the seafloor between the transmitter and receiver (Figure 13).

From the Z-scores for RX09 we find that seafloor apparent conductivity appears to be relatively highest when the transmitter was over or near to the zone of previously drilled mineralization (green square in Figure 13). This suggests that the conductive massive sulfides were successfully detected by the system. For RX11 the seafloor apparent conductivity is also slightly elevated when the transmitter was over the mineralization, though the effect is not as prominent as for RX09. This is likely because RX09 is located closer to the mineralization and therefore more sensitive to it.

Using the 3D forward modeling code, we calculate the expected apparent conductivities at RX09 for the 10 transmitter locations closest to the mineralized zone with a model consisting of $4.6 \mathrm{~S} / \mathrm{m}$ seawater, $1 \mathrm{~S} / \mathrm{m}$ seafloor, and a $30 \mathrm{~m}$ thick $10 \mathrm{~S} / \mathrm{m}$ conductive block buried $5 \mathrm{~m}$ below the seafloor with lateral extents of $35 \mathrm{x} 55 \mathrm{~m}$ (indicated by the solid-outlined green square in Figure 13). This is the same model used in generating Figures 6-11. Figure 14 shows the difference in apparent conductivity Z-score between the forward modeling results and the real data. We find that the apparent conductivity Z-scores generated by this model are too low when compared to the data (Figure 14A). We then increased the southward extent of the conductive block in increments of $10 \mathrm{~m}$; Figures 14B-D indicate a southward extension of the conductive 
block by $20 \mathrm{~m}, 40 \mathrm{~m}$, and $60 \mathrm{~m}$. We find that the best match to the apparent conductivity Z-scores of the real data occurs when the conductive block is extended $40 \mathrm{~m}$ to the south

(Figure 14c); when the mean absolute difference between modeled apparent conductivity Z-score and data is calculated, the minimum value of 0.471 occurs when the conductive target is extended southward by $40 \mathrm{~m}$. This suggests that the mineralization at Palinuro extends to the south of the drilling zone by a few 10s of meters, which is consistent with the footprint of the self-potential signal measured at the mineralized zone (Safipour et al., 2017a). In addition, this southward extension of mineralization is also consistent with heat flow measurements taken of the seafloor sediment during the POS509 research cruise in February 2017, which found elevated temperatures of up to $35.6{ }^{\circ} \mathrm{C}$ extending southward of the drilling zone by $\sim 35 \mathrm{~m}$ (Hölz, 2017).

The use of Z-scores in our analysis allows us to determine areas where the seafloor appears to be relatively more or less conductive compared to the background seafloor conductivity, which is useful in exploring for targets such as massive sulfides which are highly conductive compare to unmineralized rock. Matching of actual apparent conductivities in the data is a difficult exercise using a forward modeling approach; a 3D inversion of the data would be a better approach when there is a desire to estimate the actual, rather than relative, seafloor conductivity structure. However, a 3D inversion is computationally expensive compared to our approach. Furthermore, the data set analyzed in this study has only 2 receivers and is too sparse to provide a proper base for a full 3D inversion of the seafloor conductivity structure. A second data set was collected with the Coil2Dipole configuration during the POS509 research cruise using 10 receivers; the data from that deployment is currently being processed and will form the basis of a full 3D interpretation of the seafloor structure at Palinuro (Hölz, 2017).

\section{Conclusions}

We conducted a first test of the Coil2Dipole configuration, which is capable of 
collecting data from both a ship-towed coincident-loop receiver and remote electric dipole receivers placed on the seafloor. A 3D model of the Palinuro study area was created using bathymetry data, and 3D forward modeling results suggest that the Coil2Dipole configuration should be capable of detecting a shallowly-buried $10 \mathrm{~S} / \mathrm{m}$ conductive target block of dimensions consistent with a zone of previously drilled massive sulfide mineralization. The conductive target can be detected at receivers located up to $\sim 100 \mathrm{~m}$ away when the transmitter is located directly above the mineralized zone, and the use of a vertical transmitter over a horizontal transmitter would extend the sensitivity to the conductive target by a few 10 s of meters broadside to the transmitter loop. The sensitivity of the configuration to the conductive target decreases as the transmitter is moved away from the mineralized zone, and when the transmitter is located $100 \mathrm{~m}$ from the edge of the mineralization the receivers are only sensitive to the target when they are located directly above it. The configuration is only sensitive to the conductivity structure of the seafloor between the transmitter and the receiver. When a vertical transmitter is used, the configuration is less affected by changes in height between the transmitter and receiver and target burial depth caused by the bathymetry of the study area compared to a horizontal transmitter.

Data recorded by the remote receivers during the test of the configuration at the Palinuro Seamount were analyzed using an apparent conductivity method; results indicate higher apparent conductivities when the transmitter was close to the zone of previously drilled massive sulfide mineralization. Forward modeling also indicates a conductive target block that extends $40 \mathrm{~m}$ to the south of the drilling zone, suggesting that massive sulfide mineralization at Palinuro extends southward of the drilling zone by a few 10s of meters. This southward extension of the mineralization is consistent with self-potential and heat flow data collected at the site. Our experiment at Palinuro demonstrates that a marine TEM experiment, which only offers a shallow depth of investigation, may be extended by the inclusion of remote receivers to allow for measurements in a Coil2Dipole configuration. 
This configuration can compliment shallow TEM soundings by increasing sensitivity to deeper structure and has useful applications in the exploration of electrically conductive massive sulfide mineral deposits on the seafloor.

\section{Acknowledgements}

We wish to thank the Newmont Mining Corporation, Eldad Haber, and David Wynn for access to and assistance with the UBC forward modeling code. This project received funding from GEOMAR, The Colorado School of Mines, and the European Union as part of the Blue Mining project: Grant No. 604500, "Breakthrough Solutions for the Sustainable Exploration and Extraction of Deep Sea Mineral Resources". This is an EU-FP7 project.

\section{References}

Asakawa, E., T. Sumi, T. Yamakawa, and M. Kose, 2016, Multi-stage and Integrated Approach for Seafloor Massive Sulfide (SMS) Exploration: 22nd European Meeting of Environmental and Engineering Geophysics, Barcelona, Spain.

Cairns, G., R. Evans, and R. Edwards, 1996, A time-domain electromagnetic survey of the TAG hydrothermal mound: Geophysical Research Letters, 23, 3455-3458.

Caratori Tontini, F., G. Bortoluzzi, C. Carmisciano, L. Cocchi, C. de Ronde, M. Ligi, and F. Muccini, 2014, Near-bottom magnetic signatures of submarine hydrothermal systems at Marsili and Palinuro Volcanoes, Southern Tyrrhenian Sea, Italy: Economic Geology, 109, 2119-2128.

Constable, S., 2010, Ten years of marine CSEM for hydrocarbon exploration: Geophysics, 75, A67-A81.

Constable, S., P. Kannberg, and K. Weitemeyer, 2016, Vulcan: A deep-towed CSEM receiver: Geochemistry Geophysics Geosystems, 17, 1042-1064.

Haber, E., 2015, Computational methods in geophysical electromagnetics: Society for Industrial and Applied Mathematics. 
Hölz, S., 2017, Cruise Report POS509: Geophysical investigations of sediment hosted massive sulfide deposits on the Palinuro Volcanic Complex in the Tyrrhenian Sea, Malaga (Spain) - Catania (Italy) 15.02.-03.03.2017: GEOMAR Report, N.Ser. 039, 63 pp.

Hölz, S., M. Jegen, S. Petersen, and M. Hannington, 2015a, How to find buried and inactive seafloor massive sulfides using transient electromagnetics - A case study from the Palinuro Seamount in the Tyrrhenian Sea: Underwater Mining Institute Conference, Tampa Bay, FL, USA, 1-8.

Hölz, S., A. Swidinsky, M. Sommer, M. Jegen, and J. Bialas, 2015b, The use of rotational invariants for the interpretation of marine CSEM data with a case study from the North Alex mud volcano, West Nile Delta: Geophysical Journal International, 201, 224-245.

Kowalczyk, P., 2008, Geophysical prelude to first exploitation of submarine massive sulphides: First Break, 26, 99-106.

Ligi, M., L. Cocchi, G. Bortoluzzi, F. D’Oriano, F. Muccini, F. Tontini, C. de Ronde, and C. Carmisciano, 2014, Mapping of seafloor hydrothermally altered rocks using geophysical methods: Marsili and Palinuro seamounts, southern Tyrrhenian Sea: Economic Geology, 109, 2103-2117.

Macnae, J., and R. Irvine, 1988, Inductive source resistivity: A tool for outlining silicification in gold exploration: Exploration Geophysics, 19, 471-480.

Macnae, J., P. McGowan, and Y. Lamontagne, 1989, Resistivity mapping using inductive sources: Exploration Geophysics, 20, 47-50.

Minniti, M., and F. Bonavia, 1984, Copper-ore grade mineralization discovered in a seamount in the Tyrrhenian Sea (Mediterranean): Is the mineralization related to porphyry-coppers or to base metal lodes?: Marine Geology, 59, 271-282.

Nakayama, K., and A. Saito, 2016, The Seabed TDEM Towed by ROV for the Ocean Bottom Hydrothermal Deposits: 22nd European Meeting of Environmental and Engineering Geophysics, Barcelona, Spain.

Petersen, S., T. Monecke, A. Westhues, M. Hannington, J. Gemmell, R. Sharpe, M. Peters, 
H. Strauss, K. Lackschewitz, N. Augustin, H. Gibson, and R. Kleeberg, 2014, Drilling shallow-water massive sulfides at the Palinuro volcanic complex, Aeolian Island Arc, Italy: Economic Geology, 109, 2129-2157.

Safipour, R., S. Hölz, J. Halbach, S. Petersen, M. Jegen, and A. Swidinsky, 2017a, A self-potential investigation of submarine massive sulfides: Palinuro Seamount, Tyrrhenian Sea: Geophysics, 82, A51-A56.

Safipour, R., S. Hölz, M. Jegen, and A. Swidinsky, 2017b, On electric fields produced by inductive sources on the seafloor: Geophysics, 82, E297 - E313.

Schwalenberg, K., M. Haeckel, J. Poort, and M. Jegen, 2010a, Evaluation of gas hydrate deposits in an active seep area using marine controlled source electromagnetics: Results from Opouawe Bank, Hikurangi Margin, New Zealand: Marine Geology, 272, 79-88.

Schwalenberg, K., W. Wood, I. Pecher, L. Hamdan, S. Henrys, M. Jegen, and R. Coffin, 2010b, Preliminary interpretation of electromagnetic, heat flow, seismic, and geochemical data for gas hydrate distribution across the Porangahua Ridge, New Zealand: Marine Geology, 272, 89-98.

Singer, D., and R. Kouda, 2001, Some simple guides to finding useful information in exploration geochemical data: Natural Resources Research, 10, 137-147.

Swidinsky, A., S. Hölz, and M. Jegen, 2015, Rapid resistivity imaging for marine controlled-source electromagnetic surveys with two transmitter polarizations: An application to the North Alex mud volcano, West Nile Delta: Geophysics, 80, 1-14.

Weitemeyer, K., S. Constable, and K. Key, 2006a, First results from a marine controlled-source electromagnetic survey to detect gas hydrates offshore Oregon: Geophysical Research Letters, 33, L03304.

Weitemeyer, K., S. Constable, and K. Key, 2006b, Marine EM techniques for gas-hydrate detection and hazard mitigation: The Leading Edge, 25, 629-632.

Wolfgram, P. A., R. Edwards, L. Law, and M. N. Bone, 1986, Polymetalic sulfide exploration on the deep seafloor: The feasability of the MINI-MOSES experiment: 
Geophysics, 51, 1808-1818.

Yuan, J., and N. Edwards, 2000, The assessment of marine gas hydrates through electrical remote sounding: Hydrate without a BSR?: Geophysical Research Letters, 27, $2397-2400$. 


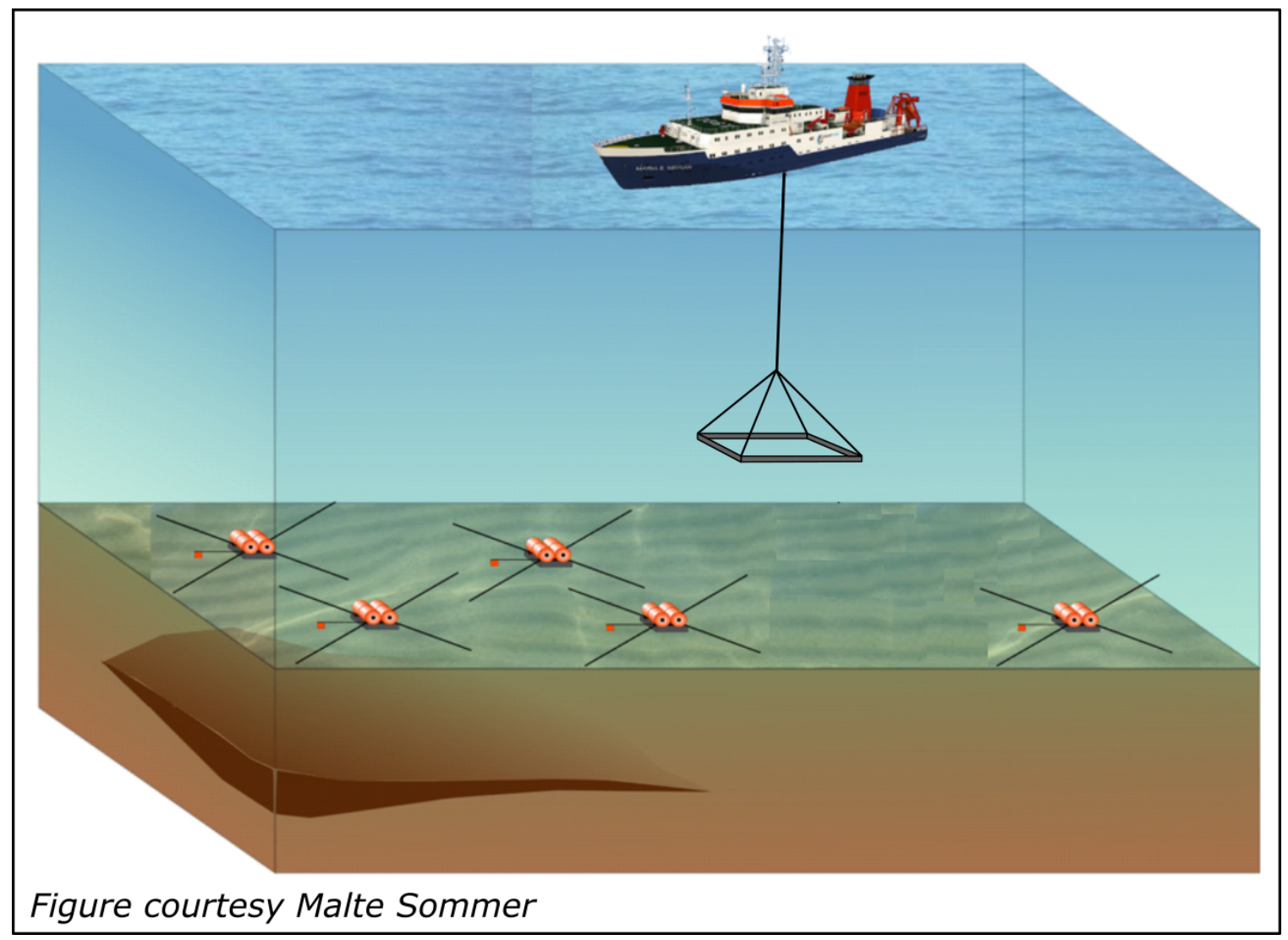

Figure 1: Illustration of the Coil2Dipole configuration, consisting of a horizontally suspended square frame housing a loop transmitter that is towed by a ship. Remote two-component electric dipole receivers are deployed on the seafloor. 


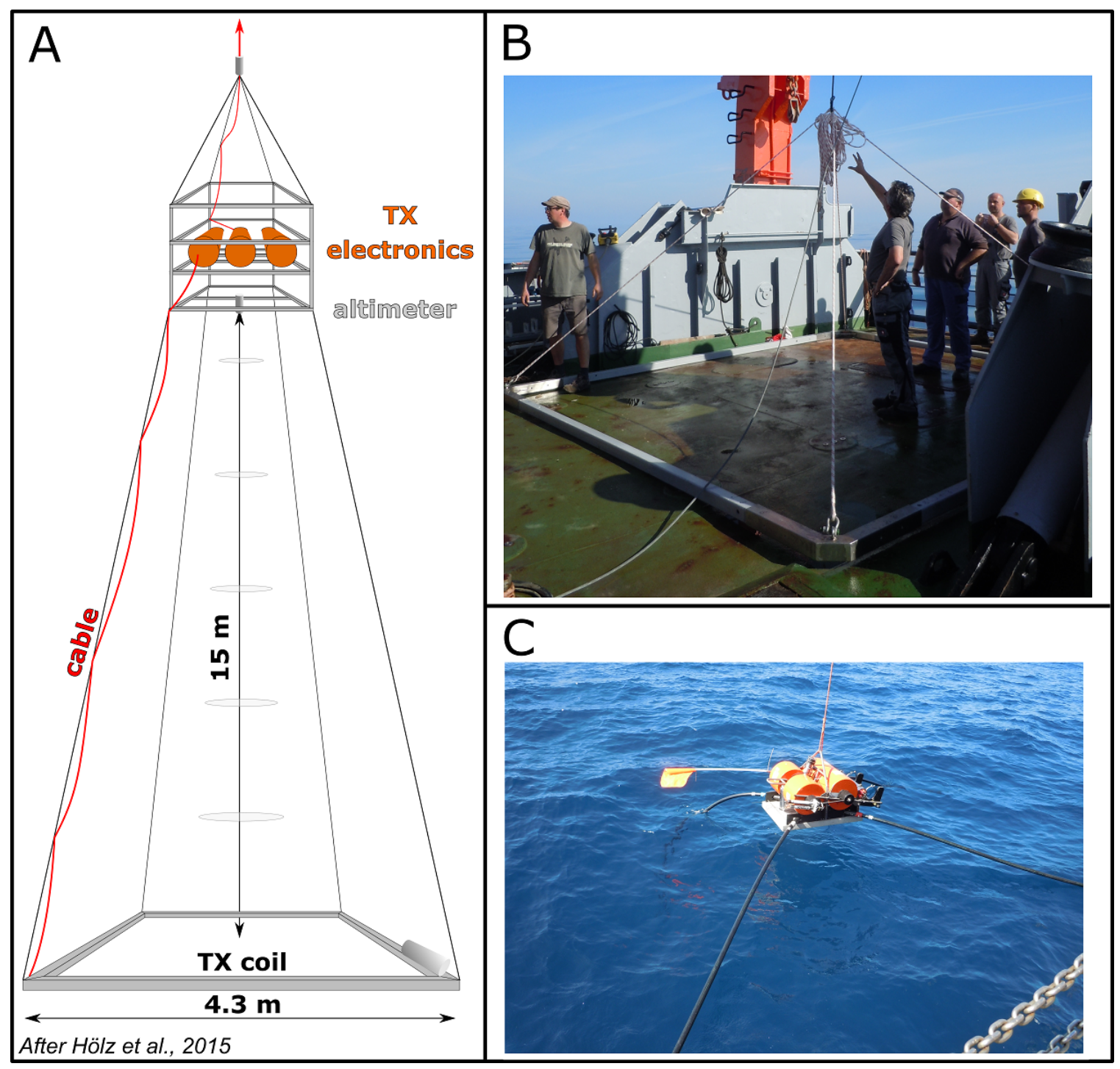

Figure 2: A) A diagram of the Coil2Dipole transmitter. B) The transmitter loop being readied for deployment. C) An ocean-bottom receiver being deployed over the side of the ship. 


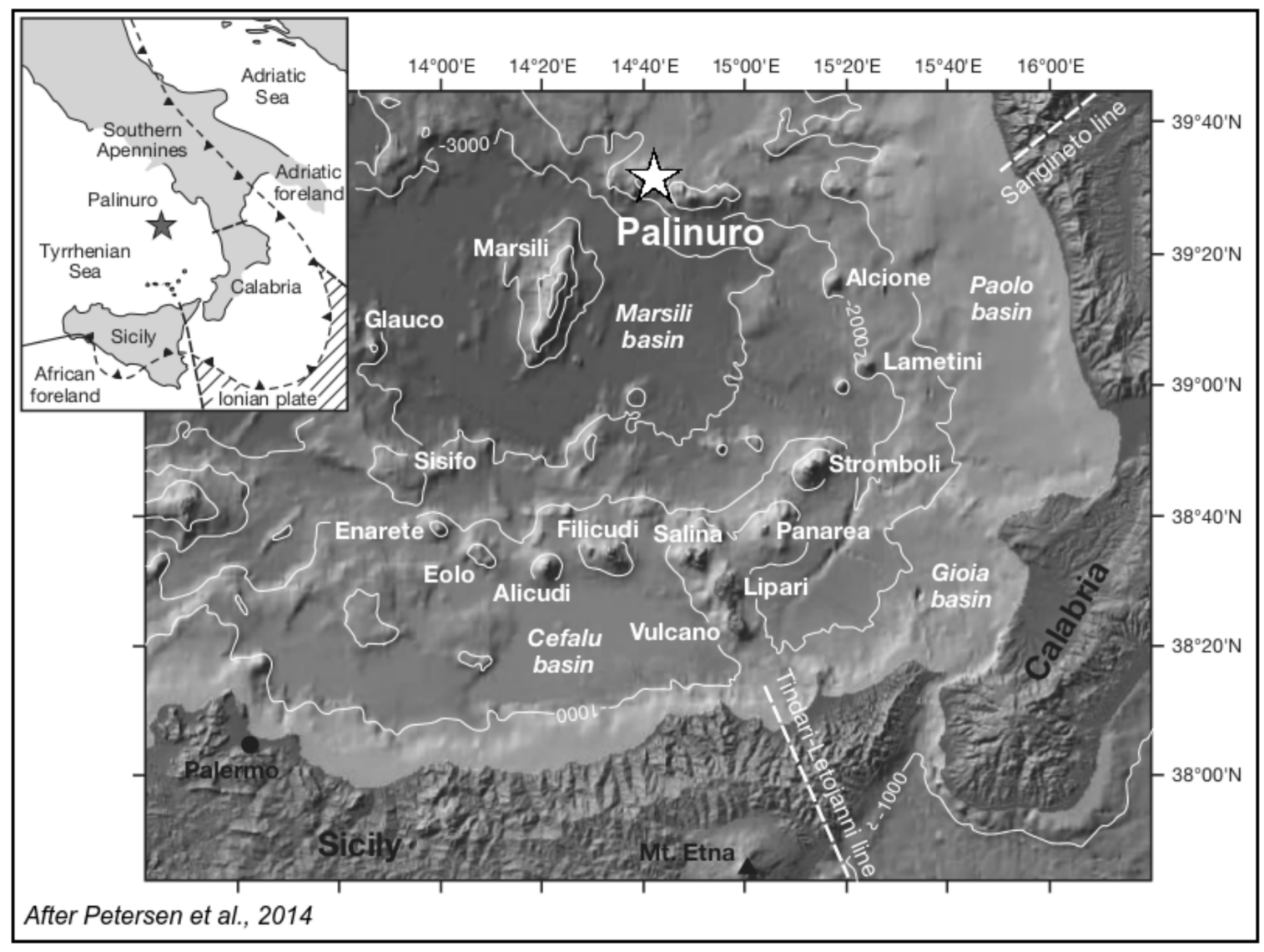

Figure 3: A map of the location of the Palinuro Seamount where the test of the Coil2Dipole configuration was conducted. 


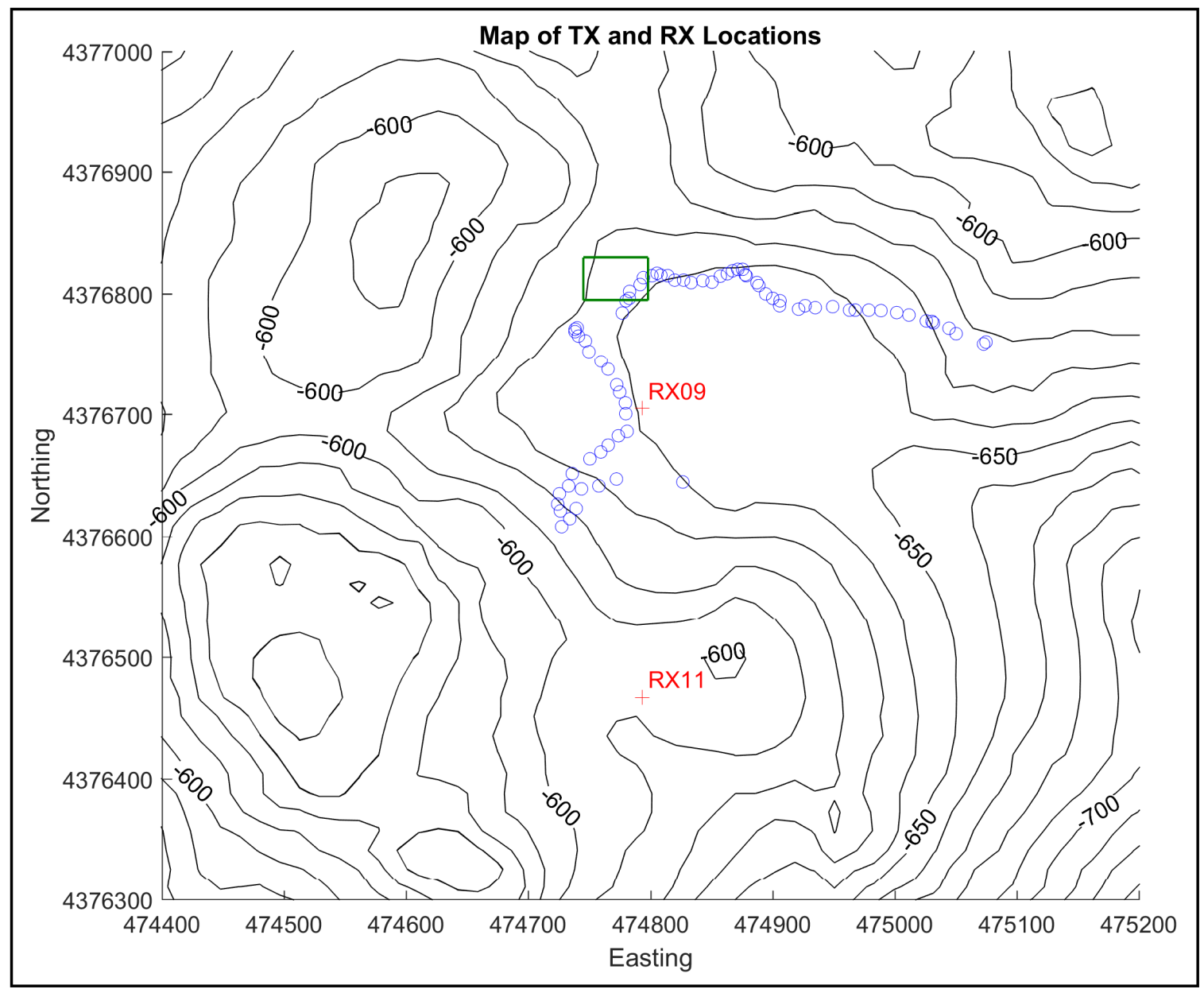

Figure 4: A map of the transmission sites (blue circles) and the locations of receivers RX09 and RX11 (red crosses). The zone of previously-drilled massive sulfide mineralization is indicated by the green square. Bathymetry is indicated by the black contours. 


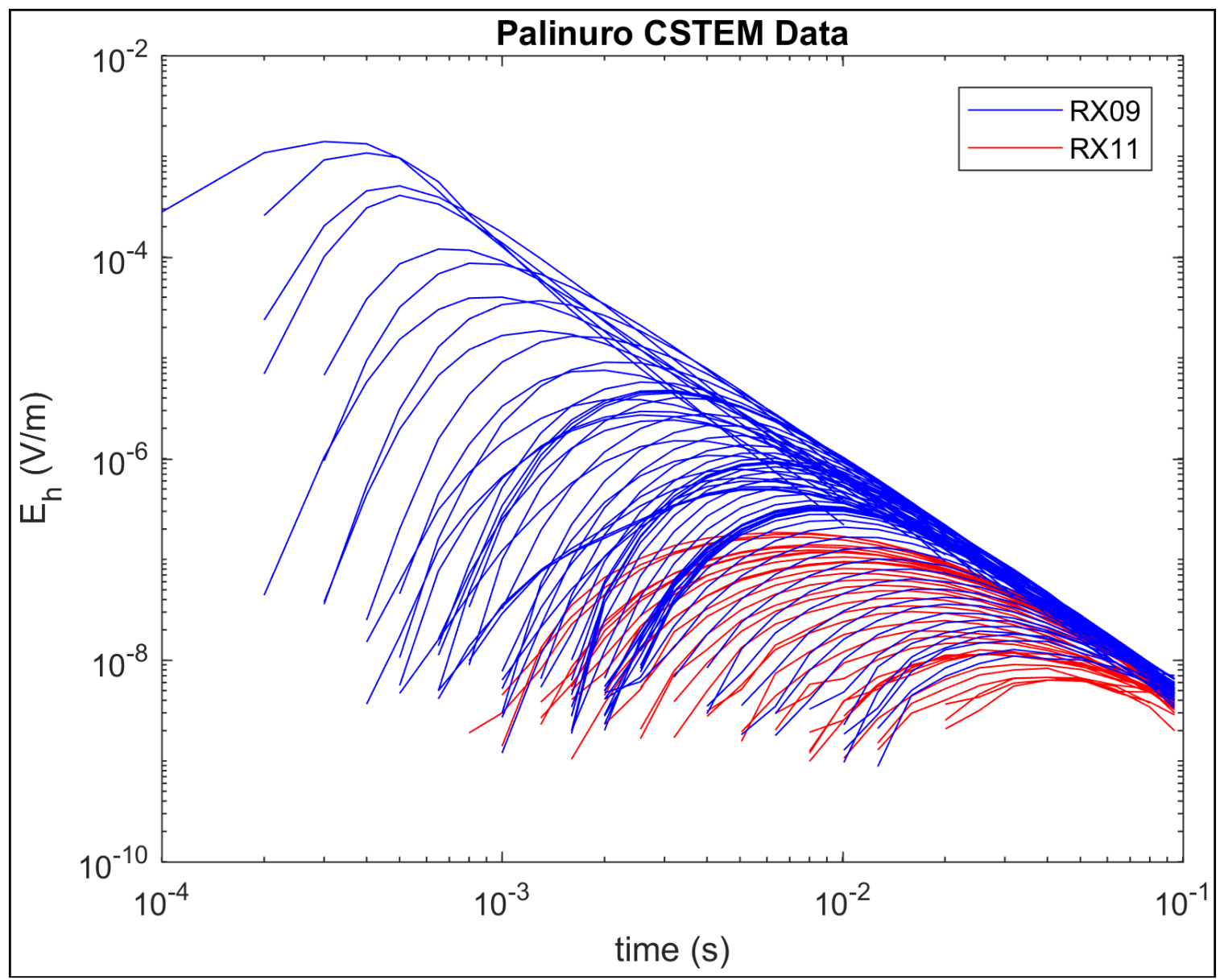

Figure 5: All transients recorded during the Coil2Dipole experiment at Palinuro by RX09 (blue curves) and RX11 (red curves). 


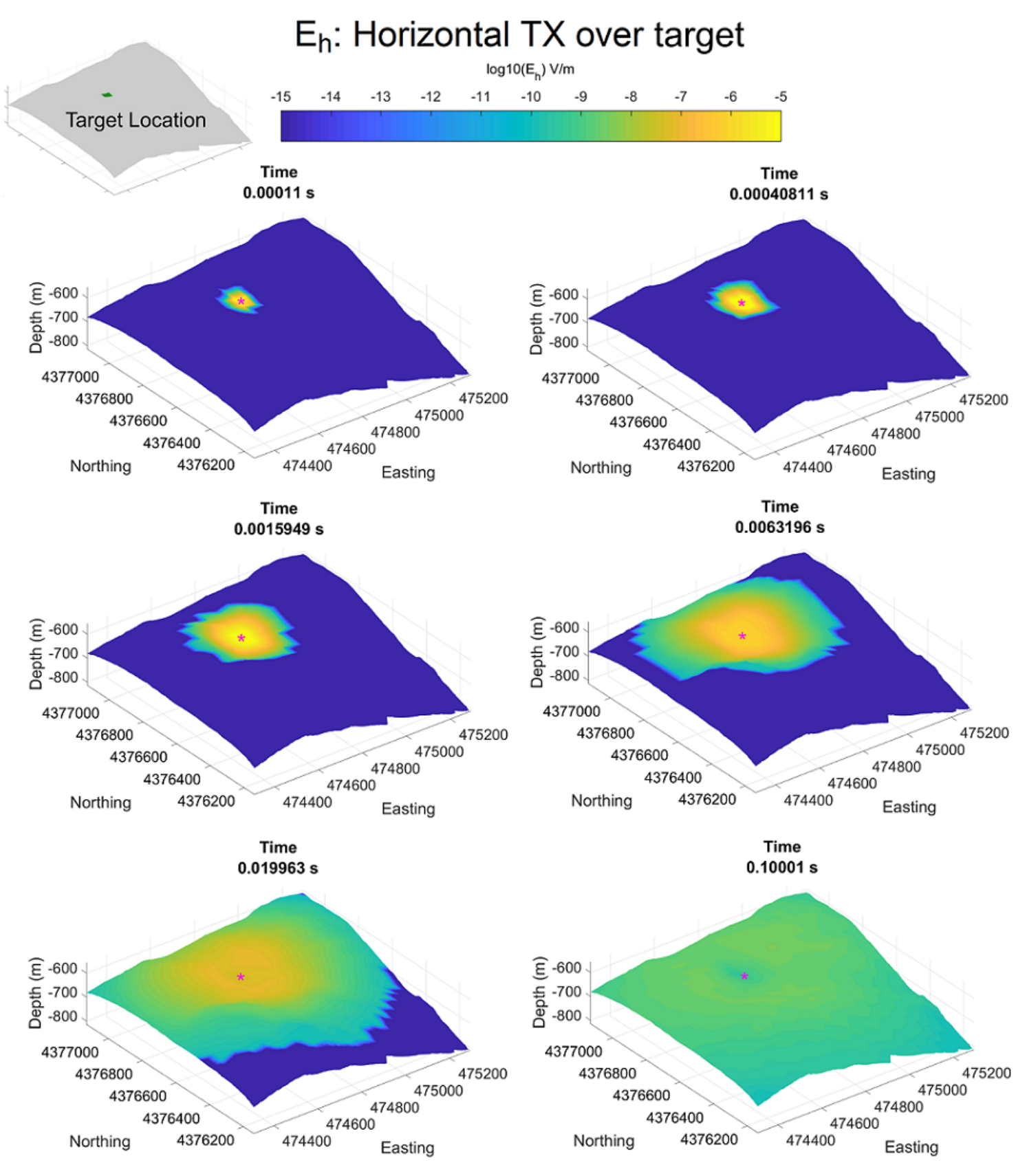

Figure 6: Forward model of the diffusion of the total horizontal electric field magnitude across the bathymetry of the Palinuro study area at six timesteps after transmitter turn-off: horizontal loop transmitter, indicated by the pink asterisk, located directly above the center of the mineralized zone. 

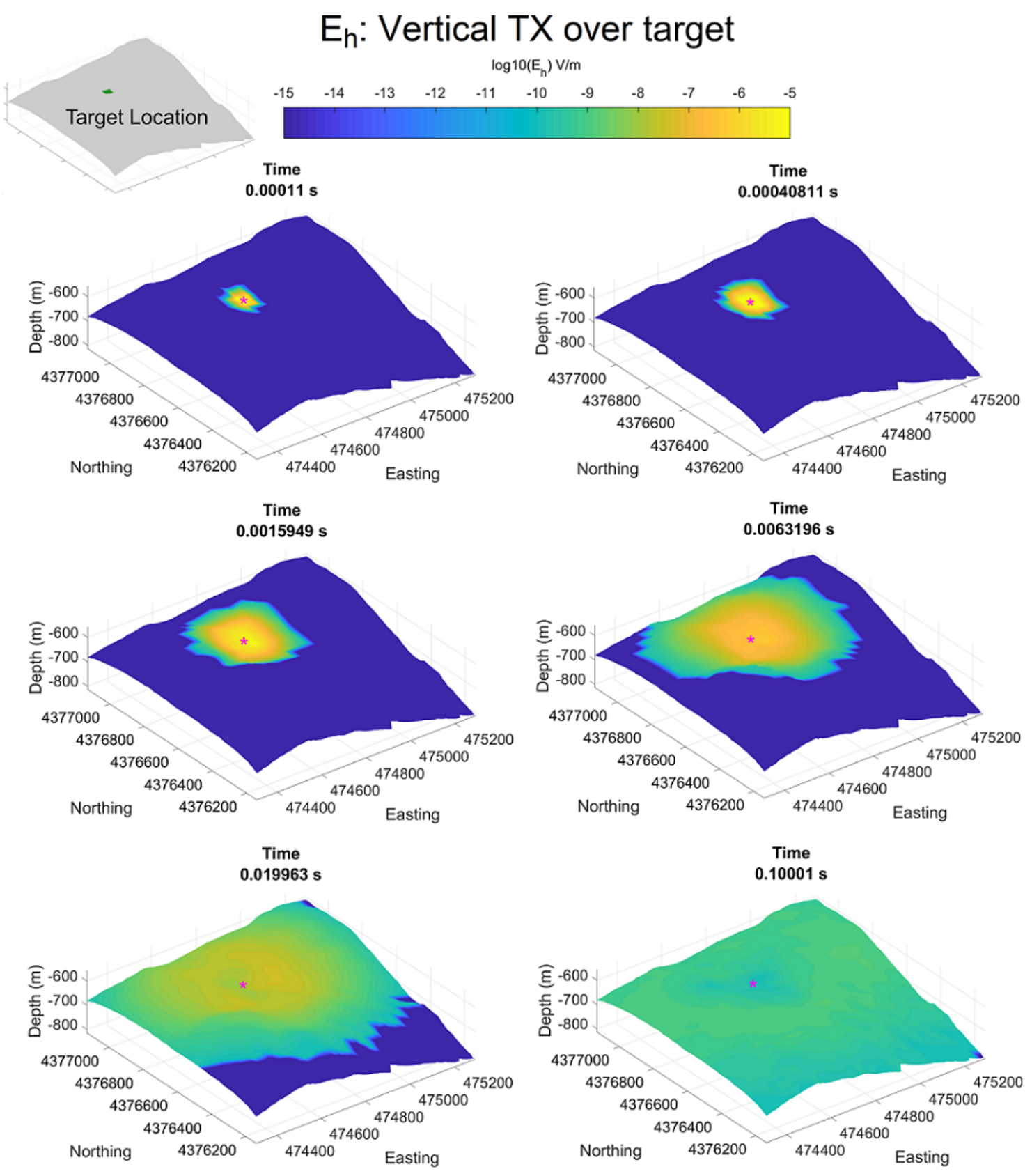

Figure 7: Forward model of the diffusion of the total horizontal electric field magnitude across the bathymetry of the Palinuro study area at six timesteps after transmitter turn-off: vertical loop transmitter, indicated by the pink asterisk, located directly above the center of the mineralized zone indicated by the pink asterisk. 

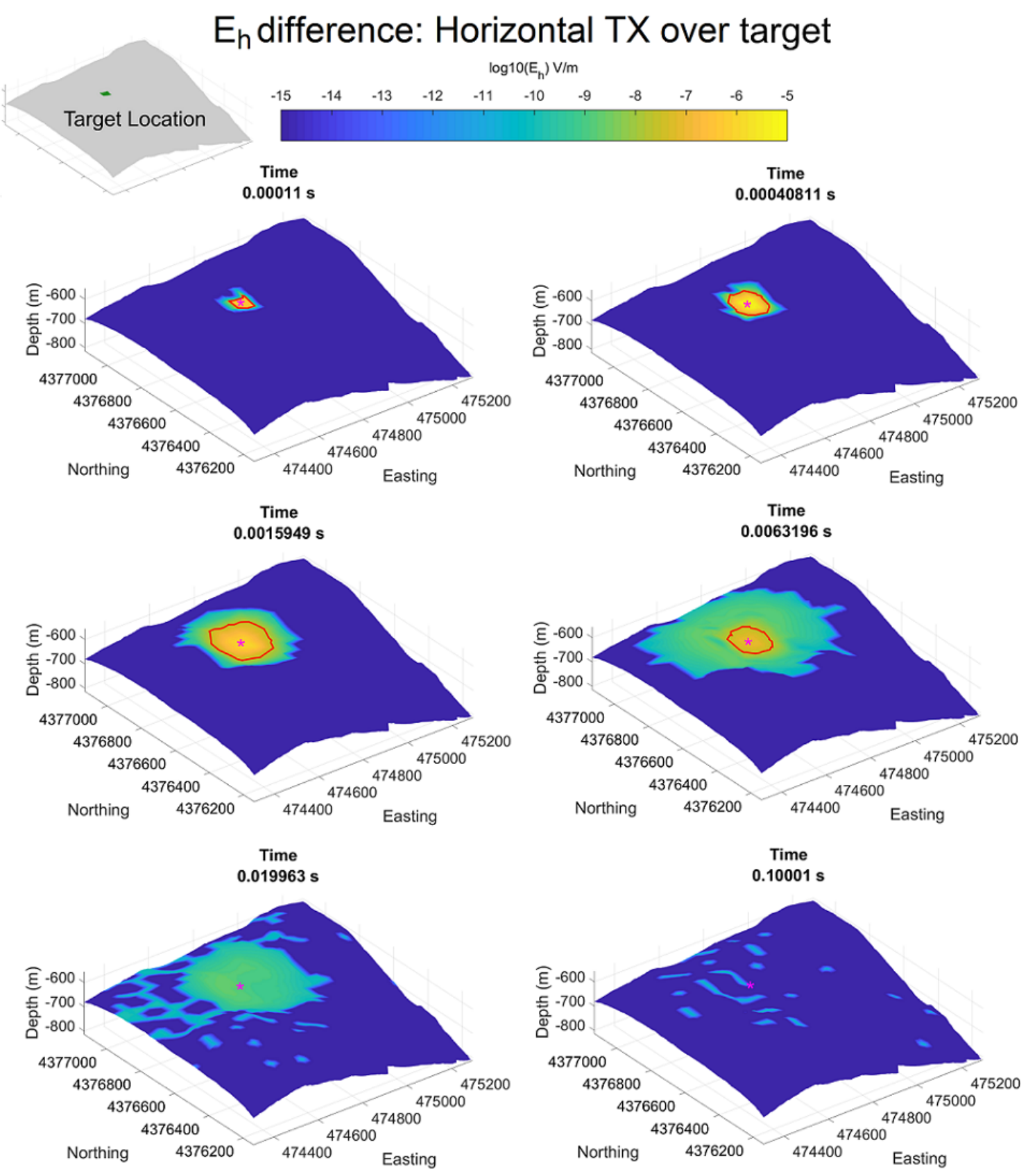

Figure 8: Forward model of the absolute difference in the total horizontal electric field magnitude for a homogeneous seafloor model vs. the model which includes the conductive target block, displayed on the bathymetry of the Palinuro study area at six timesteps after transmitter turn-off: horizontal loop transmitter, indicated by the pink asterisk, located directly above the center of the mineralized zone. Red contour indicates the noise floor of the receivers used in the experiment at $2 \times 10^{-8} \mathrm{~V} / \mathrm{m}$. 


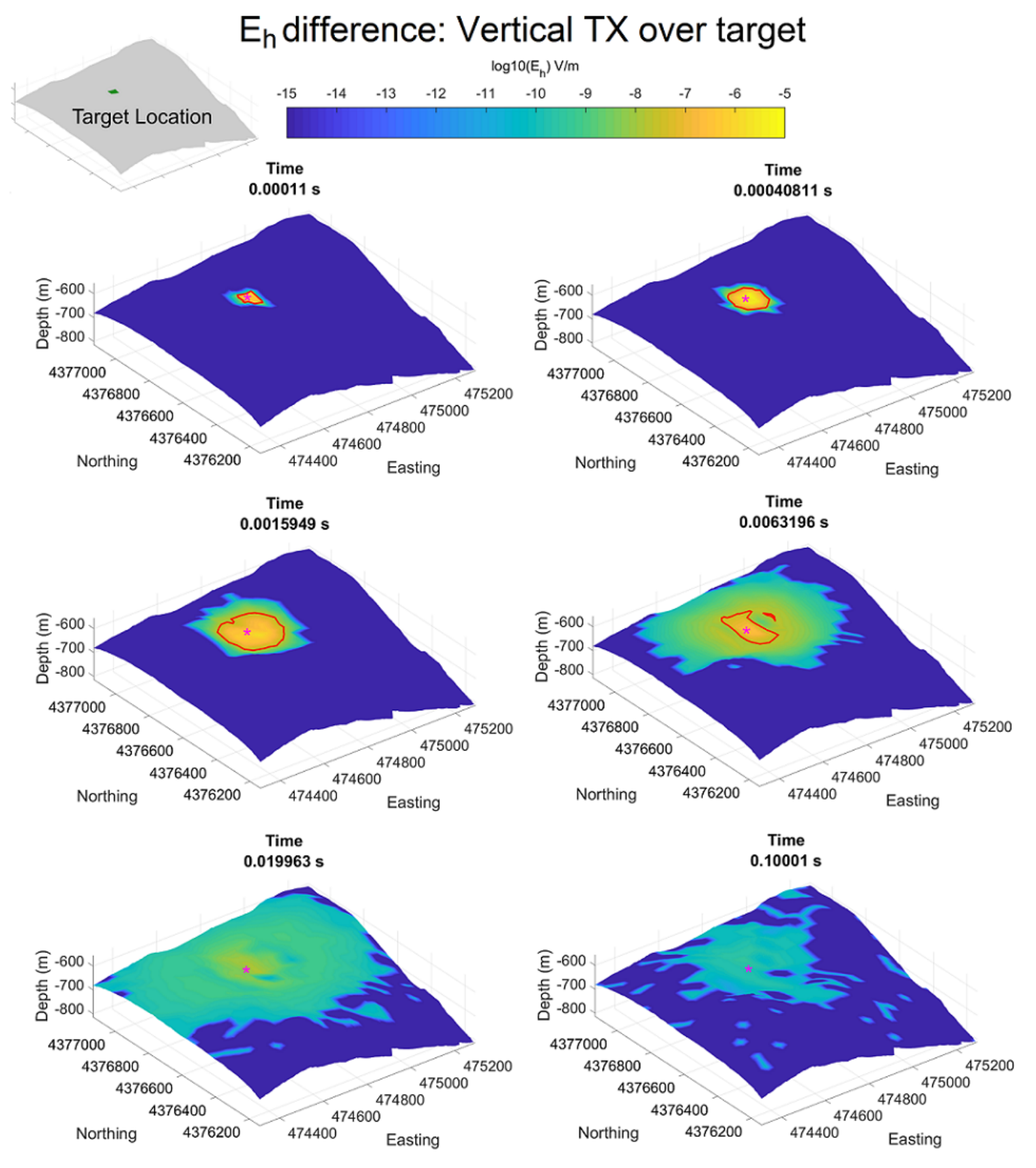

$\log 10\left(E_{h}\right) V / m$

Figure 9: Forward model of the absolute difference in the total horizontal electric field magnitude for a homogeneous seafloor model vs. the model which includes the conductive target block, displayed on the bathymetry of the Palinuro study area at six timesteps after transmitter turn-off: vertical loop transmitter, indicated by the pink asterisk, located directly above the center of the mineralized zone. Red contour indicates the noise floor of the receivers used in the experiment at $2 \times 10^{-8} \mathrm{~V} / \mathrm{m}$. 

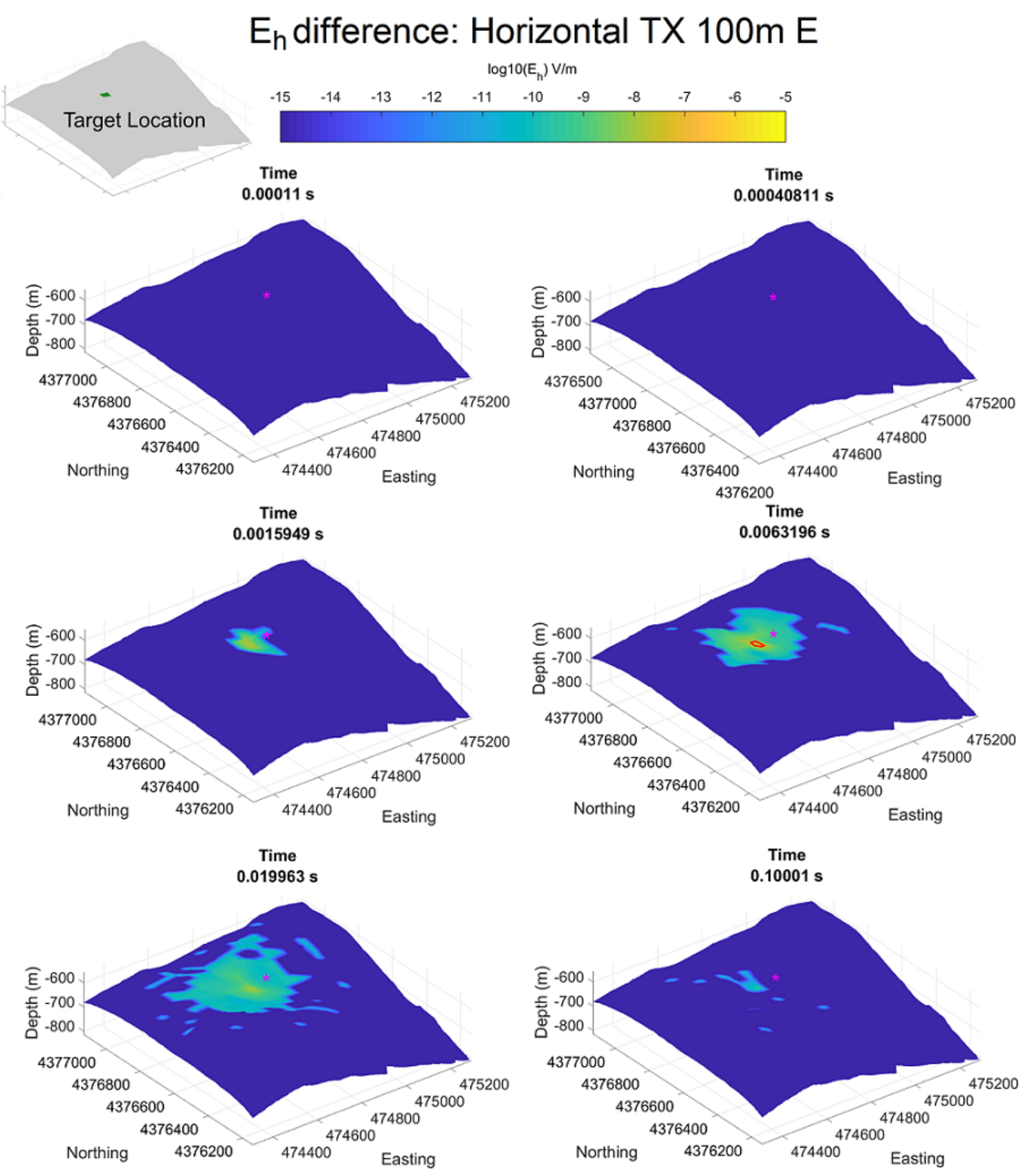

Figure 10: Forward model of the absolute difference in the total horizontal electric field magnitude for a homogeneous seafloor model vs. the model which includes the conductive target block, displayed on the bathymetry of the Palinuro study area at six timesteps after transmitter turn-off: horizontal loop transmitter, indicated by the pink asterisk, located $100 \mathrm{~m}$ to the east of the edge of the mineralized zone. Red contour indicates the noise floor of the receivers used in the experiment at $2 \times 10^{-8} \mathrm{~V} / \mathrm{m}$. 

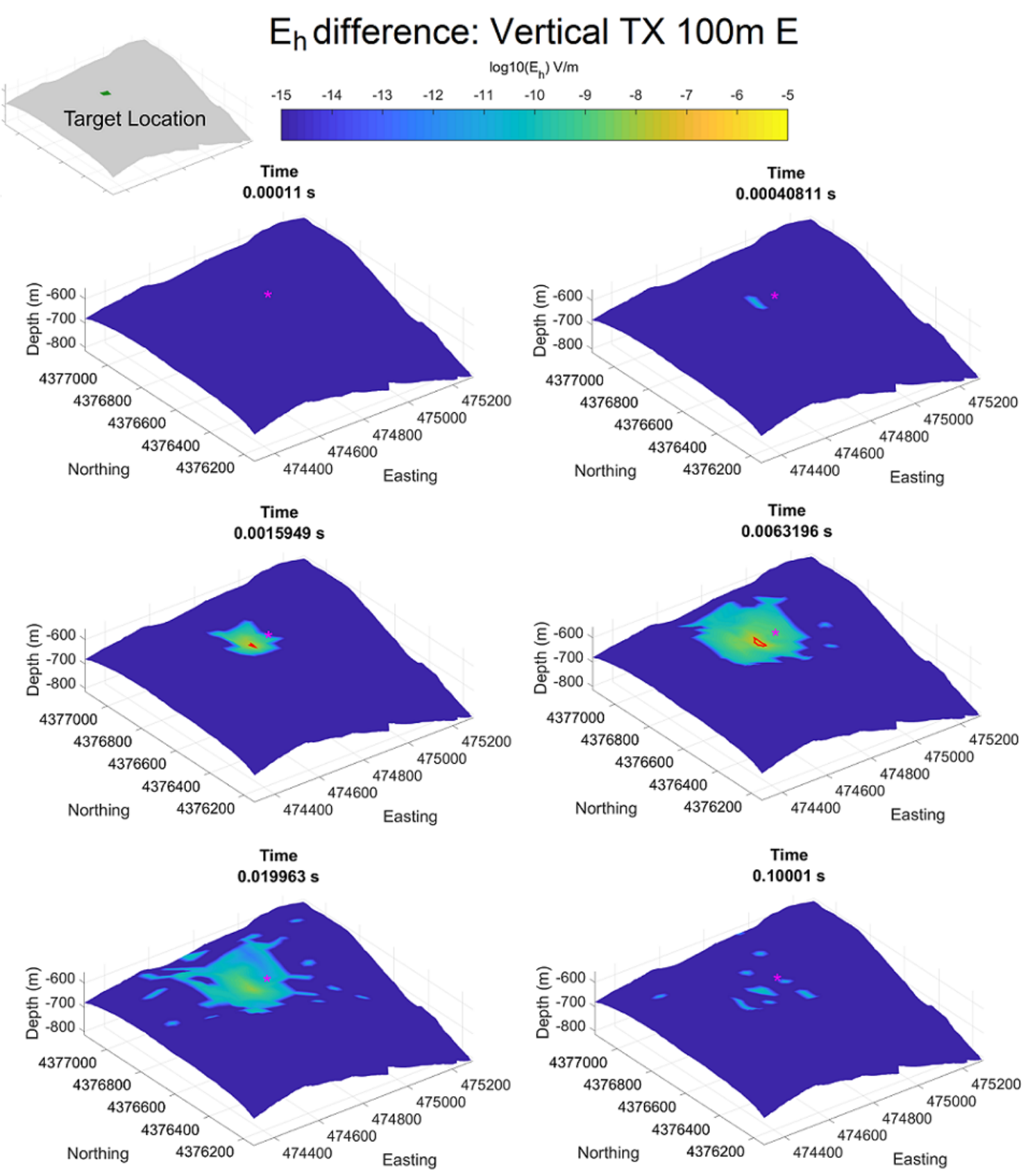

Figure 11: Forward model of the absolute difference in the total horizontal electric field magnitude for a homogeneous seafloor model vs. the model which includes the conductive target block, displayed on the bathymetry of the Palinuro study area at six timesteps after transmitter turn-off: vertical loop transmitter, indicated by the pink asterisk, located 100 $\mathrm{m}$ to the east of the edge of the mineralized zone. Red contour indicates the noise floor of the receivers used in the experiment at $2 \times 10^{-8} \mathrm{~V} / \mathrm{m}$. 


\section{Model Cross Section}
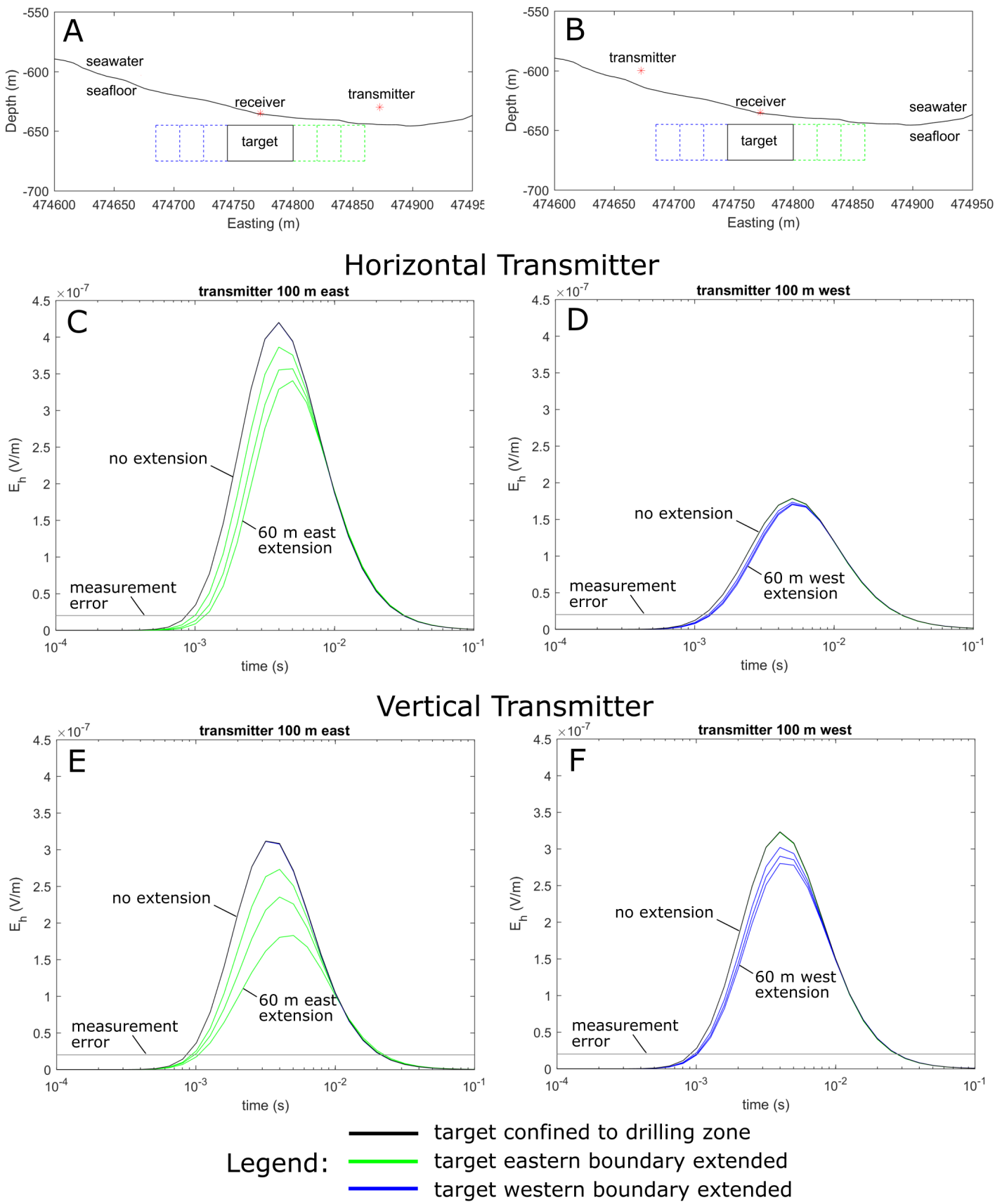

Figure 12: Plots of the total horizontal electric field magnitude, $E_{h}$, vs time at a receiver located on the seafloor centered over the conductive target. Green lines indicate a model with the target boundary extended to the east by $20 \mathrm{~m}, 40 \mathrm{~m}$, and $60 \mathrm{~m}$. Blue lines indicate a model with the target boundary extended to the west by $20 \mathrm{~m}, 40 \mathrm{~m}$, and $60 \mathrm{~m}$. Black lines indicates a model with the target boundary confined to the drilling zone (green 
square in Figure 4). The approximate measurement error of the receivers used in the experiment, $2 \times 10^{-8} \mathrm{~V} / \mathrm{m}$, is indicated by the gray line. A) Cross section of the model with transmitter located $100 \mathrm{~m}$ east of receiver. B) Cross section of the model with transmitter located $100 \mathrm{~m}$ west of receiver. C) Horizontal transmitter located $10 \mathrm{~m}$ above the seafloor $100 \mathrm{~m}$ east of receiver. D) Horizontal transmitter located $10 \mathrm{~m}$ above the seafloor $100 \mathrm{~m}$ west of receiver. E) Vertical transmitter located $10 \mathrm{~m}$ above the seafloor $100 \mathrm{~m}$ east of receiver. F) Vertical transmitter located $10 \mathrm{~m}$ above the seafloor $100 \mathrm{~m}$ west of receiver. 


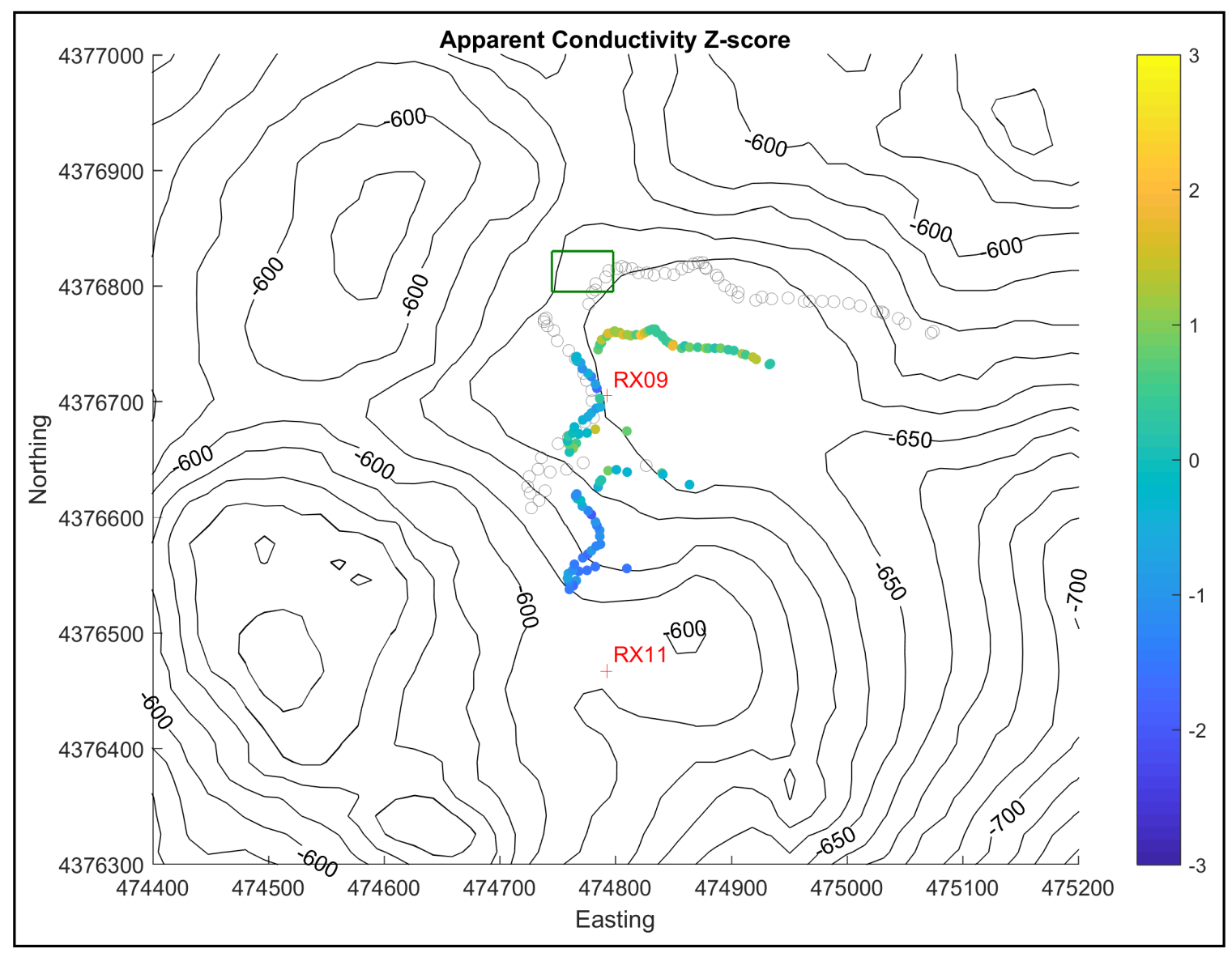

Figure 13: Z-scores of apparent conductivity of the seafloor calculated from the transients recorded by RX09 and RX11. Transmitter locations are indicated by the gray circles and receiver locations are indicated by the red crosses. The zone of previously-drilled massive sulfide mineralization is indicated by the green square. Bathymetry is indicated by the black contours. 
Apparent Conductivity Z-score Difference from Data

A. No Deposit Extension

B. $20 \mathrm{~m}$ Deposit Extension
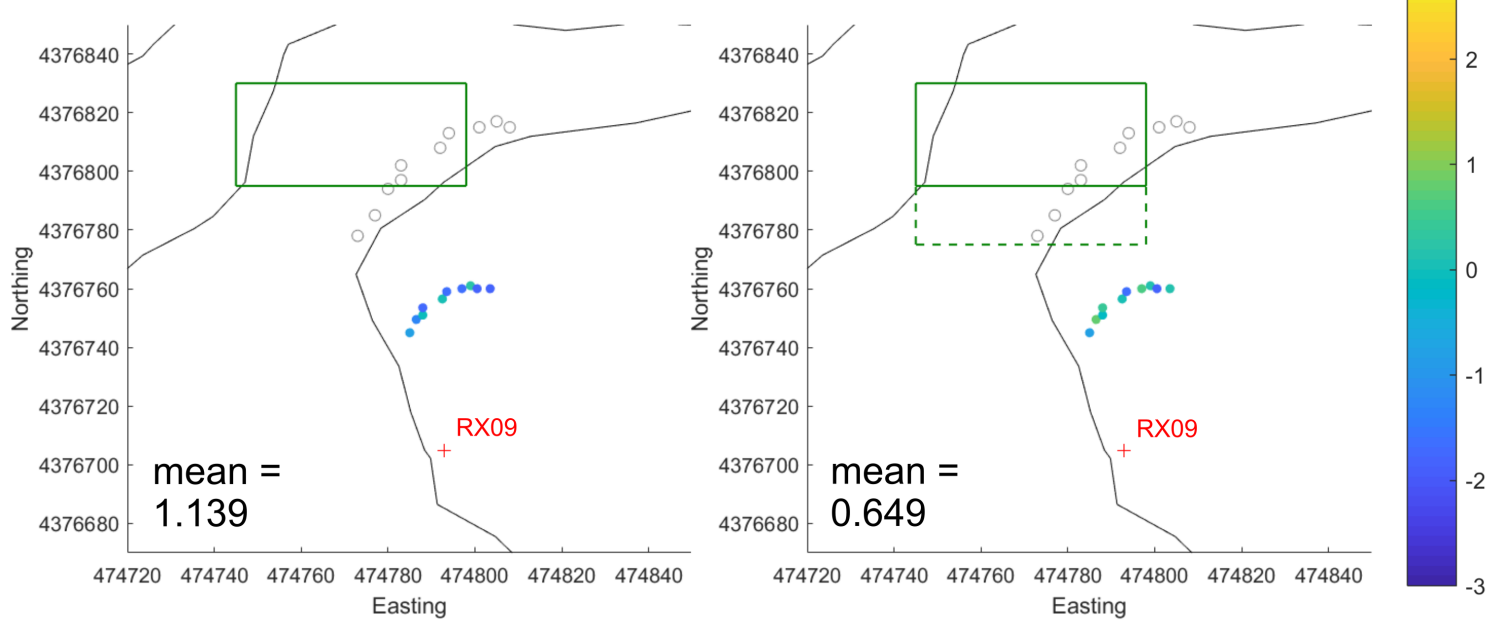

C. $40 \mathrm{~m}$ Deposit Extension

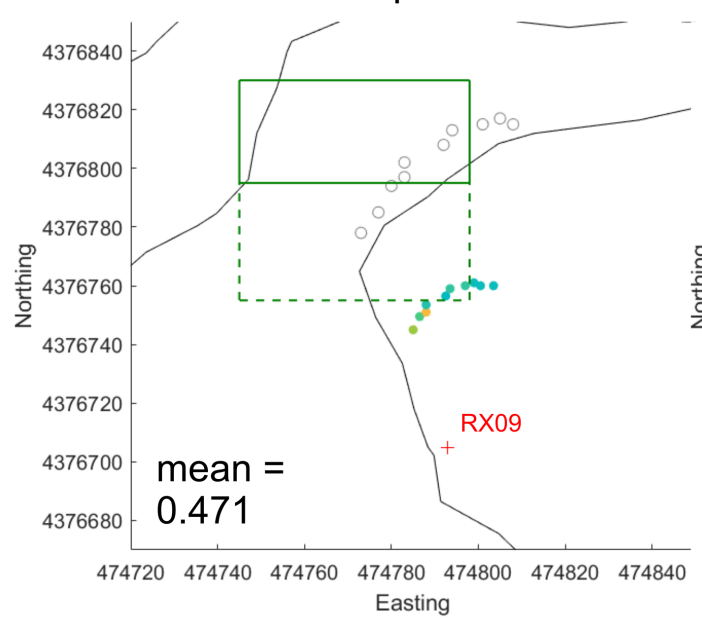

D. $60 \mathrm{~m}$ Deposit Extension

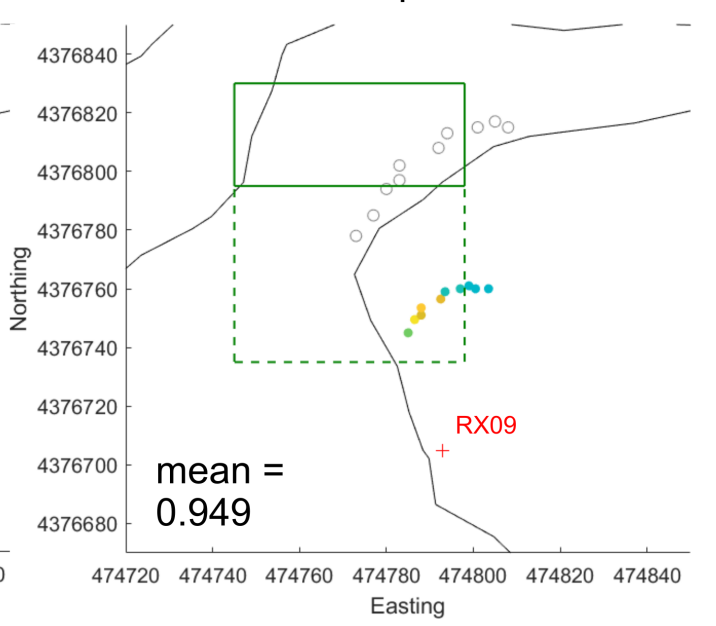

Figure 14: Difference in Z-scores of apparent conductivity between forward model and data. Transmitter locations are indicated by the gray circles and receiver RX09 location is indicated by the red cross. The zone of previously-drilled massive sulfide mineralization is indicated by the solid-line green square. Green dashed lines indicate the southward extension of the conductive target block in the model. Mean absolute difference in Z-score is indicated in the lower left of each panel. A) No southward extension. B) $20 \mathrm{~m}$ southward extension. C) $40 \mathrm{~m}$ southward extension. D) $60 \mathrm{~m}$ southward extension. 